\title{
THE INFLUENCE OF PARENTAL AND PEER ATTACHMENT ON SELF-ESTEEM AT LATE ADOLESCENCE
}

\author{
Migena Kecaj ${ }^{1}$, Edmond Rapti $^{2}$, Aigars Andersons ${ }^{3}$
}

\begin{abstract}
The present study investigates the relationship between parent and peer attachment bonds on the development of self-esteem during late adolescence. The sample was randomly selected. Data was collected from 387 participants including 166 male and 221 female students from seven high schools of the Shkoder Municipality in Albania. A self-developed Demographic Questionnaire, Inventory of Parent and Peer Attachment (Armsden \& Greenberg, 1987) and Rosenberg Self Esteem Scale (Rosenberg, 1965) were administered. A Pearson Correlation and Independent sample t-test were applied. Specific attention is focused on the assessment of attachment in adolescence. The results show the existence of a significant positive correlation between parental/peer attachment and self-esteem. Concerning gender differences during late adolescence, females showed higher attachment with parents and peers than males, but there were no gender differences in self-esteem. This research enables us to develop new insight into the importance of parent and peer attachment for a healthy adolescence.
\end{abstract}

UDC Classification: 159.942 , DOI: https://doi.org/10.12955/pss.v2.220

Keywords: attachment; development; parent; peer; self-esteem.

\section{Introduction}

Attachment is an enduring (Stein et al., 2002) and universal emotional connection with another person. Attachment between children and parents develops very early and happens in all cultures. Children get attached to their parents in their first years of life. Bowlby (1958) was the pioneer of the attachment theory. The four main characteristics of this relation are: proximity maintenance-the child wishes to become close with their caregivers; safe haven-the child comes to his parents when he feels fear; secure base- the care givers provide security and separation distress-the child feels anxiety in the absence of caregivers (Rayan, 2010). Meanwhile, Mary Ainsworth (1970) who was the follower of Bowlby's' attachment theory developed a technique named "the strange-situation" to observe attachment styles. The two most important patterns of attachment are secure and insecure base and are developed based on parental responses. Appleyard and Berlin (2007) explain that the secure attachment is based on the parent's positive and sensible responses towards their children, whereas insecure attachment is developed as result of parent's insensitive and irresponsible attitude towards their children. The two patterns of attachment have a greater impact on adolescents' development affecting their cognitive, social and emotional functioning during their transitional stage from childhood to adulthood.

As we know, during adolescence teens become more attached with their peers and social relations and less with their parents (Harris Jr, 1995). Even though, the pattern of attachments with their parents continues and accompanies the way the adolescents connect with themselves, their peers and others. Attachment and relationship patterns that we have with our peers, partners, and social groups are reflections of the primary attachment we had with our primary caregiver during infant phase. It is well documented that securely attached children in infancy are more likely to be involved in reciprocal friendships and have higher numbers of friends than insecure children (Elicker et al., 1992; Grossman and Grossman, 1991).

An important topic of our paper is to explore the influence of parent and peer attachment on the development of self-esteem. Studies document that during adolescence, not only the quality of attachment with parents but also with peers is positively related to the individual's self-esteem, selfefficacy (Bandura et al., 2001), wellbeing, social engagement (Iyer et al., 2010), etc. Self-esteem as defined by Rosenberg (1965) is used to describe a person's overall sense of self-worth or personal value, and the framework of the internal working model is closely related to self-esteem development (Bowlby, 1973). It is documented by Cummings and Cicchetti (1990) that a supportive and trusting relationship with parents is expected to facilitate the development of a positive view of self as capable and lovable, meanwhile children who experience an insecure parent-child attachment relationship may feel rejected and unwanted and tend to have lower self-esteem.

\footnotetext{
${ }^{1}$ University of Shkoder "Luigj Gurakuqi”, Faculty of Education Sciences, Shkodër, Albania, migena.selcetaj@unishk.edu.al

${ }^{2}$ University of Tirana, Faculty of Social Sciences, Tirana, Albania, edi_rapti@yahoo.com

${ }^{3}$ Vidzeme University of Applied Sciences, Institute of Social, Economic and Humanities Research of Vidzeme University of Applied Sciences, Vidzeme, Latvia, aigars.andersons@va.lv
} 


\section{Research Methodology}

The purpose of conducting this research was to investigate the bonds between parental attachment and peer attachment with their self-esteem. It was a descriptive and correlational study. The statistical sample included 387 adolescents who were selected through stratified random sampling at seven high schools in the Shkoder Municipality. The population was comprised of male $(\mathrm{N}=166)$ and female $(\mathrm{N}=221)$ adolescents studying at the high schools of Shkoder during the academic year 2018-2019.

Demographic questionnaire. The demographic questionnaire requires adolescents to indicate their age, gender, and class.

IPPA questionnaire: To assess Parent Attachment an Inventory of Parent and Peer Attachment (IPPA) questionnaire was used. The IPPA questionnaire was developed in order to assess adolescents' perceptions of the positive and negative affective/cognitive dimension of relationships with their parents and close friends particularly how well these figures serve as sources of psychological security (Armsden \& Greenberg, 1987). The instrument is a self-reporting questionnaire with a five-point Likert -scale response format (Likert Scale: 1- Almost Never or Never True to 5- Almost True or Always True) and with 25 items. The original version consists of 28 parents' items and 25 peer items, yielding two attachment scores. The IPPA is scored by reverse-scoring the negatively worded items and then summing the response values in each section. The alpha reliability of the IPPA inventory is 0.875 .

Self Esteem Scale: Adolescents self- esteem was assessed using the Rosenberg (1965) Self-Esteem Scale (RSES). The scale consists of 10 items answered using a four-point Likert scale ranging from 'strongly disagree' (0) to 'strongly agree' (3). Five negatively stated items are reverse scored. Individual scores are summed to determine an overall score where higher scores represent greater self-esteem (Rosenberg, 1965). Internal consistency of the scale was 0.79 .

\section{Results}

The results on the attachment of adolescents in this study are presented in the tables and graphs below:

\begin{tabular}{|c|c|c|c|c|}
\hline \multirow[t]{3}{*}{ Sample } & \multicolumn{2}{|l|}{ Gender } & \multicolumn{2}{|l|}{ Age } \\
\hline & $\mathrm{F}$ & $\mathrm{M}$ & 16-17 & $17-18$ \\
\hline & $221(57.1 \%)$ & $166(42.9 \%)$ & $162(42 \%)$ & $225(58 \%)$ \\
\hline Total & 387 & & & \\
\hline
\end{tabular}

Table 1 shows the number of the sample divided based on gender and group age. More female adolescents $(57.1 \%)$ were studied than male adolescents (42.9\%), and more 17-18 year-old adolescents (58\%) were studied than 16-17 year-old adolescents (42\%).

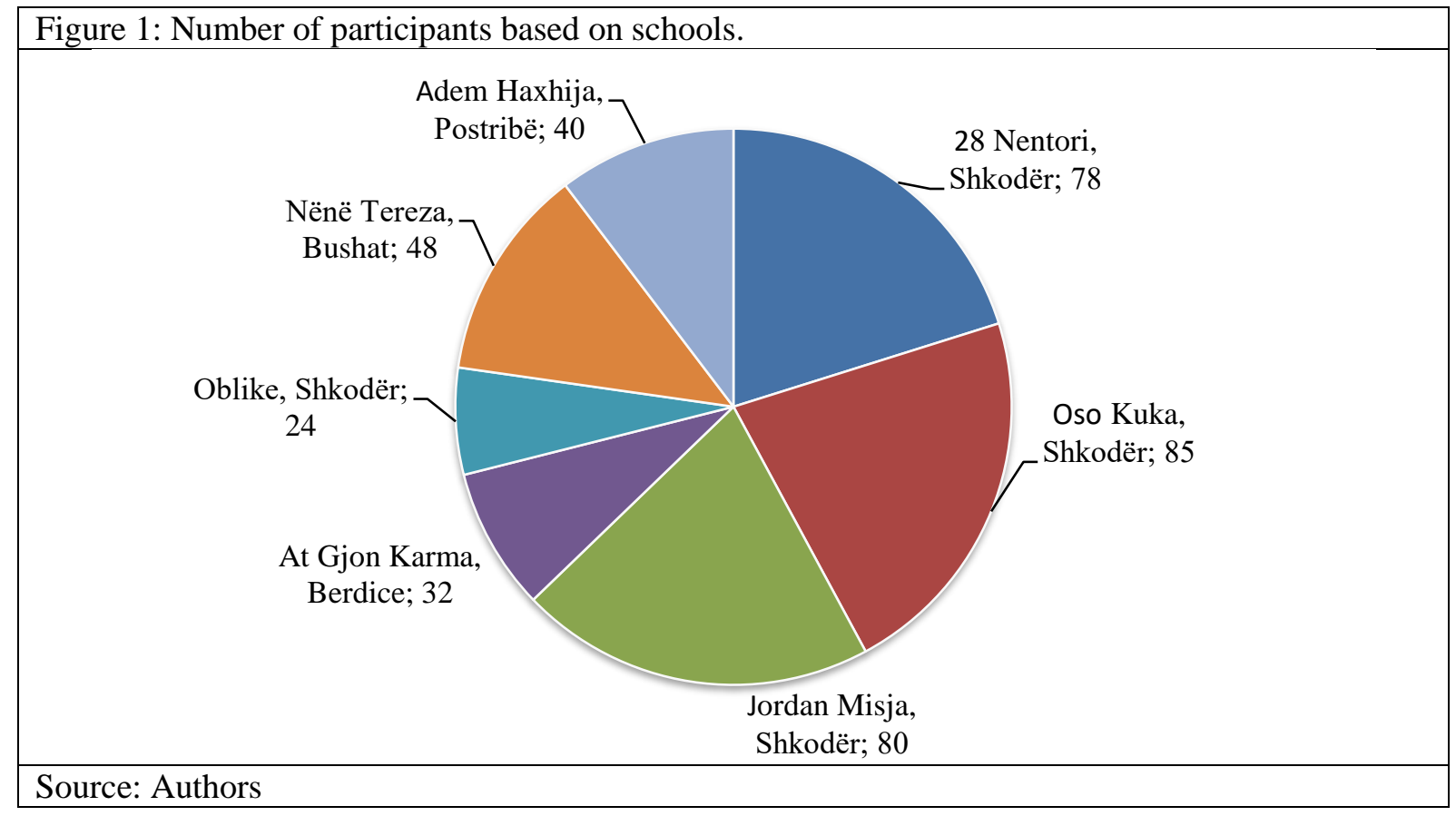


Figure 1, shows the number of the participants in the study divided based on which high school they attended. There were 78 pupils/participants from " 28 Nëntori" high school; 85 pupils of "Oso Kuka" high school; 80 pupils of "Jordan Misja" high school; 32 pupils of "At Gjon Karma" high school, Bërdicë, Shkoder; 48 pupils of "Nënë Tereza" high school, Bushat; and 40 pupils of "Adem Haxhija" high school, Postribë, Shkoder.

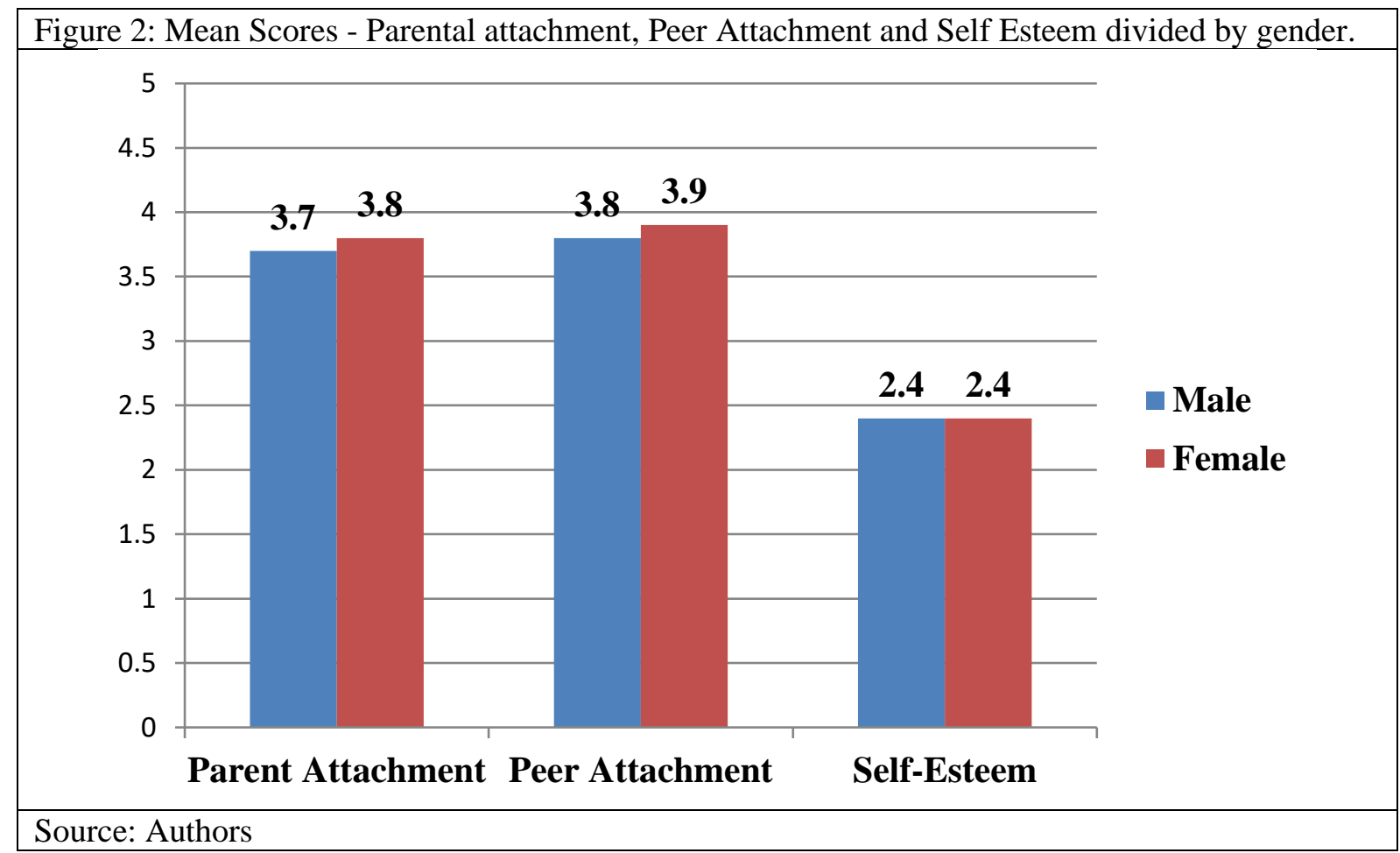

Figure. 2 shows the mean score of parental attachment, peer attachment and self-esteem to male and female groups. These results indicate that male adolescents mostly reported positive relationships with their parents and peers with a slight difference on the average between two variables; being more attached with their peers than their parents ( $M=3.7$ parent attachment; $M=3.8$ peer attachment). Female adolescents as the male adolescents showed the same differences regarding parent attachment and peer attachment. They are more attached with their peers than with the parents $(\mathrm{M}=3.8$ parent attachment; $\mathrm{M}=3.9$ peer attachment). Regarding self-esteem, adolescents of both genders had the same level of selfesteem $(M=2.4)$. Taking in consideration the Rosenberg scores, the adolescents had results which indicated a normal range of self-esteem.

\begin{tabular}{|c|c|c|c|c|}
\hline & & Self Esteem & $\begin{array}{l}\text { Parent } \\
\text { Attachment }\end{array}$ & $\begin{array}{l}\text { Peer } \\
\text { Attachment }\end{array}$ \\
\hline \multirow[t]{3}{*}{ Self-Esteem } & Pearson Correlation & 1 & $0.308^{* *}$ & $0.322^{* *}$ \\
\hline & $\mathrm{p}$ & & $<0.001$ & $<0.001$ \\
\hline & $\mathrm{N}$ & 212 & 212 & 212 \\
\hline \multirow[t]{3}{*}{ Parental Attachment } & Pearson Correlation & $0.308^{* *}$ & 1 & $0.998^{* *}$ \\
\hline & $\mathrm{p}$ & $<0.001$ & & $<0.001$ \\
\hline & $\mathrm{N}$ & 212 & 218 & 218 \\
\hline \multirow[t]{3}{*}{ Peer Attachment } & Pearson Correlation & $0.322^{* *}$ & $0.998^{* *}$ & 1 \\
\hline & $\mathrm{p}$ & $<0.001$ & $<0.001$ & \\
\hline & $\mathrm{N}$ & 212 & 218 & 218 \\
\hline \multicolumn{5}{|c|}{$* *$ Correlation is significant at the 0.01 level (2-tailed) } \\
\hline \multicolumn{5}{|l|}{ A Gender $=$ female } \\
\hline \multicolumn{5}{|l|}{ Source: Authors } \\
\hline
\end{tabular}

The results revealed that there was a positive correlation between self-esteem and peer attachment $(\mathrm{r}=0.32, \mathrm{p}<0.01)$ at females. The degree of relation was medium between these two variables, but stronger than when regarding the correlation between self-esteem and parental attachments. There was a positive correlation between self-esteem and parental attachments $(r=0.30, p<0.01)$. 


\begin{tabular}{|c|c|c|c|c|}
\hline & & Self Esteem & $\begin{array}{l}\text { Parent } \\
\text { Attachment }\end{array}$ & Peer Attachment \\
\hline \multirow[t]{3}{*}{ Self -Esteem } & Pearson Correlation & 1 & $0.350^{* * *}$ & $0.356^{* * *}$ \\
\hline & $\mathrm{p}$ & & $<0.001$ & $<0.001$ \\
\hline & $\mathrm{N}$ & 161 & 161 & 161 \\
\hline \multirow[t]{3}{*}{ Parental Attachment } & Pearson Correlation & $0.350^{* * *}$ & 1 & $0.997^{* *}$ \\
\hline & $\mathrm{p}$ & $<0.001$ & & $<0.001$ \\
\hline & $\mathrm{N}$ & 161 & 165 & 165 \\
\hline \multirow[t]{3}{*}{ Peer Attachment } & Pearson Correlation & $0.356^{* *}$ & $0.997^{* *}$ & 1 \\
\hline & $\mathrm{p}$ & $<0.001$ & $<0.001$ & \\
\hline & $\mathrm{N}$ & 161 & 165 & 165 \\
\hline
\end{tabular}

Table 3 revealed that there was a positive correlation between self-esteem, parental attachment and peer attachment at the same level $(r=0.35, \mathrm{P}<0.01)$ in males. The degree of relation was stronger and equal between these three variables.

\section{Discussion}

The purpose of conducting this research was to assess the relationship of parental and peer attachment with self-esteem development during late adolescence. Parental and peer attachment play a major role in self-esteem during late adolescence. The results showed that there was a significant positive relationship between parental and peer attachment bonds and a significant positive relationship between peer attachment bonds and self-esteem development. There was no gender difference in self-esteem between male and female participants. There was a small difference in parental and peer attachment where females are more attached to parents and peers than males. Parents should pay attention to attachment with their children as this affects their children's psycho-social and intrapersonal/interpersonal process development. They should know well the neurocognitive, emotional and social changes that occur during adolescence. Having a positive self-esteem allows them to try new things, take healthy risks, and advance in a right way. Such experiences enable children to develop the necessary social skills and learn to display appropriate emotional responses (Kobak and Sceery, 1988).

\section{Conclusions}

The findings of this study must be viewed in the context of its limitation. We should consider that the sample consisted only of adolescents who were residing in the Shkoder Municipality restricting the generalizability of the findings. We aimed to understand the association between parental and peer attachment to self-esteem in order to provide the information needed to improve parental and adolescent's relationships in Albanian contexts. It is very important to guide and support parents so that they know how their behavior influences the later life of their children when they become adolescents and adults. Parents, education professionals, psychologists, and social workers should be knowledgeable about adolescent development and the value of adolescent-parent and peer attachment.

\section{References}

Ainsworth, M. D., \& Bell, S. M. (1970). Attachment, exploration, and separation: Illustrated by the behavior of one-year-olds in a strange situation. Child Development, 41(1), 49-67. https://doi.org/10.2307/1127388

Armsden, G. C., \& Greenberg, M. T. (1987). The Inventory of Parent and PeerAttachment: Individual differences and their relationship to psychological well-being in adolescence. Journal of Youth and Adolescence, 16(5), 427-453.

Appleyard, K., Berlin, L.J. (2007). Supporting healthy relationship between young children and their parents. Center for child and family process: Duke.

Bandura, A., Barbaranelli, C., Caprara, G. V., \& Pastorelli, C. (2001). Self-efficacy beliefs as shapers of children's aspirations and career trajectories. Child Development, 72 (1), 187-206.

Bowlby, J. (1958). The nature of the child's tie to his mother. International Journal of Psychoanalysis, 39, 350-373.

Bowlby, J. (1973) Attachment and Loss: Volume 2. Separation. New York: Basic Books.

Cummings, E. M. and Cichetti, D. (1990) 'Toward a Transactional Model of Relations Between Attachment and Depression', in M. T. Greenberg, D. Cichetti and E. M., Cummings (eds) Attachment in Preschool Years: Theory, Research, and Intervention, pp. 339-72. Chicago, IL: University of Chicago. Press. 
Elicker, J., Englund, M., \& Sroufe, L. A. (1992). Predicting peer competence and peer relationships in childhood from early parent-child relationships. In R. D. Parke \& G. W. Ladd (Eds.), Family-peer relationships: Modes of linkage (p. 77-106). Lawrence Erlbaum Associates, Inc

Grossman, K. E. and Grossman, K. (1991) 'Attachment Quality As An Organizer of Emotional and Behavioral Responses in A Longitudinal Perspective', in C. M. Parkes, J. Stevenson-Hinde and P. Morris (eds) Attachment Across the Lifecycle, pp 93-114. London: Routledge.

Harris JR. Where is the child's environment? A group socialization theory of development. Psychol Rev. 1995;102:458-89.

Iyer, R., Kochenderfer-Ladd, B., Eisenberg, N., \& Thompson, M. (2010). Peer victimization and effortful control: Relations to school engagement and academic achievement. Merrill-PalmerQuarterly,56, 361-387. doi:10.1353/mpq.0.0058

Kobak, R. R. and Sceery, A. (1988) 'Attachment in Late Adolescence: Working Models, Affect Regulation, and Representations of Self and Others', Child Development 59; 135-46.

Rayan, K. O. (2010). Attachment relationship: Nurturing healthy bonds. Chicago.: Learning seed.

Rosenberg, M. (1965). Society and the adolescent self-image. Princeton, NJ: Princeton University Press point. New York: McGraw-Hill.

Stein, H., Koontz, A. D., Fonagy, P., Allen, J. G., Fultz, J., Brethour, J. R., Jr., Allen, D., \& Evans, R. B. (2002). Adult attachment: What are the underlying dimensions? Psychology and Psychotherapy: Theory, Research and Practice, 75(1), 7791. https://doi.org/10.1348/147608302169562 